\title{
THE SOLUBILITY OF MAGNESIUM CARBONATE IN AQUEOUS SOLUTIONS OF CERTAIN ELECTROLYTES
}

\section{BY F. K. CAMERON AND A. SEIDELI,}

The work herein described was done in connection with and for the most part antedated that upon the solubility of calcium carbonate in solutions of other salts, which has already been described. ${ }^{2}$

The solubility of magnesium carbonate is obviously dependent upon the partial pressure of the carbon dioxide in the atmosphere or gas phase in contact with the solution. This has led to the development of this investigation in three parts :

r. When the solutions were in contact with ordinary atmospheric air containing a small and practically constant percentage of carbon dioxide.

2. When the atmosphere in contact with the solutions contained practically nothing but carbon dioxide and water.

3. When the solutions were in contact with an atmosphere practically free from carbon dioxide.

Under these several conditions the ratio of normal carbonate to hydrogen carbonate or bicarbonate for any given concentration of solution might be expected to vary greatly.

Moreover, it was found, in the case of solutions of magnesium carbonate, that temperature changes frequently produced relatively large changes in the solubility, and it was therefore necessary to take precautions to prevent variations in this respect during the progress of the work.

Unless otherwise stated the work described here was done at $23^{\circ} \mathrm{C}$.

As is well known, solution studies of magnesinm carbonate, when other salts are present, have always given great difficulty

\footnotetext{
${ }^{1}$ Published by the permission of the Secretary of Agriculture.
}

${ }^{2}$ Jour. Phys. Chem. 6, 50 (1902). 
it is generally believed on account of an unusually strong tendency toward the formation of complex or double carbonates. ${ }^{x}$ The work here described has involved these difficulties to a large degree, and they have delayed the announcement of the results obtained. On account of these difficulties, the results obtained when measurable quantities of carbon dioxide were present in the vapor phase, are not satisfactory, at least from a quantitative point of view, although an unusual amourit of labor was expended in obtaining them. It has seemed wisest, therefore, to present them for what they are worth as at least approximately correct, since it has become inexpedient for us to give further time to this particular investigation.

\section{In Equilibrium with Air}

A series of solutions of sodium chloride was prepared, pure powdered magnesium carbonate added, and, by means of an aspirator and appropriate connections, a stream of air was conducted through the solutions for periods ranging from 20 to roo days. Portions of the solutions were then withdrawn with a pipette, the relative amounts of carbonates and bicarbonates determined by titrating with a standard acid, using phenolphthal- . eine and methyl orange, ${ }^{2}$ respectively, as indicators. The total amount of magnesium in solution was determined gravimetrically as the pyrophosphate; and the sodium chloride by titrating with a standard solution of silver nitrate, using potassium chromate as indicator.

A number of such series of determinations was made, yielding results which approximated each other, but which could not, however, be regarded as in satisfactory agreement. It is not, therefore, thought worth while to tabulate the figures actually obtained, but the nature of the solubility curve and its approximate position are given in the accompanying chart.

In the attempt to obtain conditions which would bring

${ }^{1}$ Bodländer. Zeit. phys. Chem. 35, 3I (1900), suggests that magnesium carbonate, in going into solution, forms more or less indefinite complexes of the type $m \mathrm{Mg}(\mathrm{OH})_{2} n \mathrm{MgCO}_{3}$, to which the difficulties encountered are due.

${ }^{2}$ Vide. Am. Chem. Jour. 23, 47 I (Ig00). 
about final, definite equilibria in these solutions, several devices were used. The solutions were brought to boiling, then allowed to cool and stand for long periods while a current of air was drawn through them. In another series, magnesium carbonate was precipitated in the solutions by adding equivalent amounts of magnesium chloride and sodium carbonate. Still another plan was tried, the series of solutions being prepared as usual, but instead of bubbling air through them, a carbon dioxide generator was attached and a stream of the gas drawn through the series of solutions. It was evident that the gas rapidly caused the solution of the solid magnesium carbonate in contact with the solutions, since in several of the flasks the amount originally added soon disappeared, and it was necessary to add more. After introducing carbon dioxide for about 3 or 4 hours,

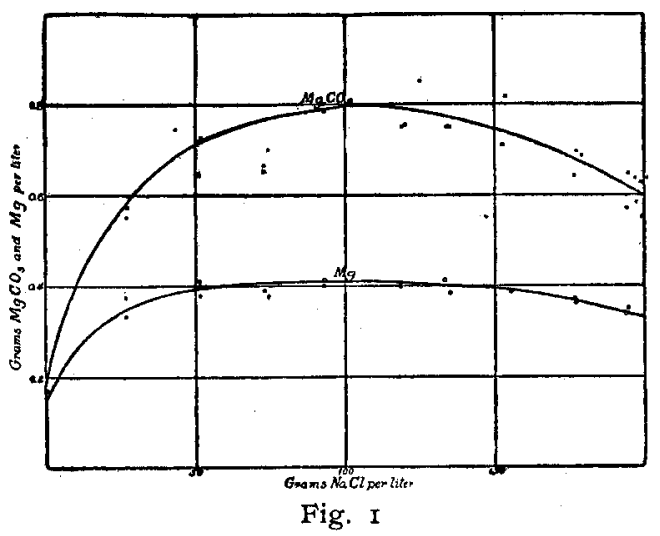

in order to insure the solution of much more of the magnesium carbonate than would dissolve without its aid, the gas generator was removed and air drawn through for the purpose of displacing the excess of carbon dioxide which had been added, and at the same time precipitate from solution the excess of magnesium carbonate which had been dissolved. The current of air which was drawn through the solutions for about ro hours did not cause the precipitation of magnesium carbonate in any of the solutions except one, where a cloudiness, which might have been due to this cause, was observed. It is needless to say satisfactory results could not be expected from these solutions. Even 
long-continued boiling failed to completely remove the excess of carbon dioxide, as titration with phenolphthaleine and methyl orange as indicators showed.

The results of these different methods of work, in general, confirmed those diagrammatically presented here. In no case were they of such a character as to lead us to believe that they could be regarded as more than rough approximations to the truth.

\section{In Equilibrium with an Atmosphere of Carbon Dioxide}

Sodium chloride solutions of various concentrations were prepared as described for the previous experiments. The volumes of the solutions for convenience, however, were kept somewhat less, about roo cubic centimeters. The solutions were introduced into small bottles of about 250 cc capacity, which were of such dimensions that they fitted into the places provided for them in a very efficient shaking apparatus. An excess of magnesium carbonate was added to each bottle and at the same time a few drops of phenolphthaleine. Carbon dioxide gas from a tube of liquid carbon dioxide after being passed through dilute sulphuric acid, was bubbled into each bottle separately until the red color disappeared. The bottles were then placed in the shaking apparatus and shaken for several hours. The red color reappeared in each flask, and upon the removal of the stopper for the purpose of introducing the tube for bubbling in more carbon dioxide, a "popping" sound was produced, caused by a diminished pressure in the inside, due to the absorption of the carbon dioxide gas which was above the solution in the bottle before it had been shaken in the apparatus.

The introduction of more carbon dioxide gas served to dispel the red color of the phenolphthaleine the second time, and after a second period of shaking, the color again reappeared in some of the bottles. It is to be noted, however, that the popping sound, caused by the removal of the stoppers, continued with every bottle, even after a great many introductions of carbonic acid gas and subsequent shaking of the bottles. Indeed, the apparently large volume of carbon dioxide which seemed to be 
absorbed by the solutions in each flask, led to the idea that part of the solid carbonate in each bottle might be uniting with the gas, and therefore becoming transformed into the unknown solid magnesium bicarbonate. An attempted demonstration of this by analysis of some of the solid phase proved futile, however, since the results apparently showed that the solid material was undoubtedly still in the form of the normal carbonate. The solubility of magnesium bicarbonate in solutions of sodium chloride is shown in the following table, and illustrated in the accompanying chart.

Solubility of Magnesium Bicarbonate in Aqueous Solutions of Sodium Chloride

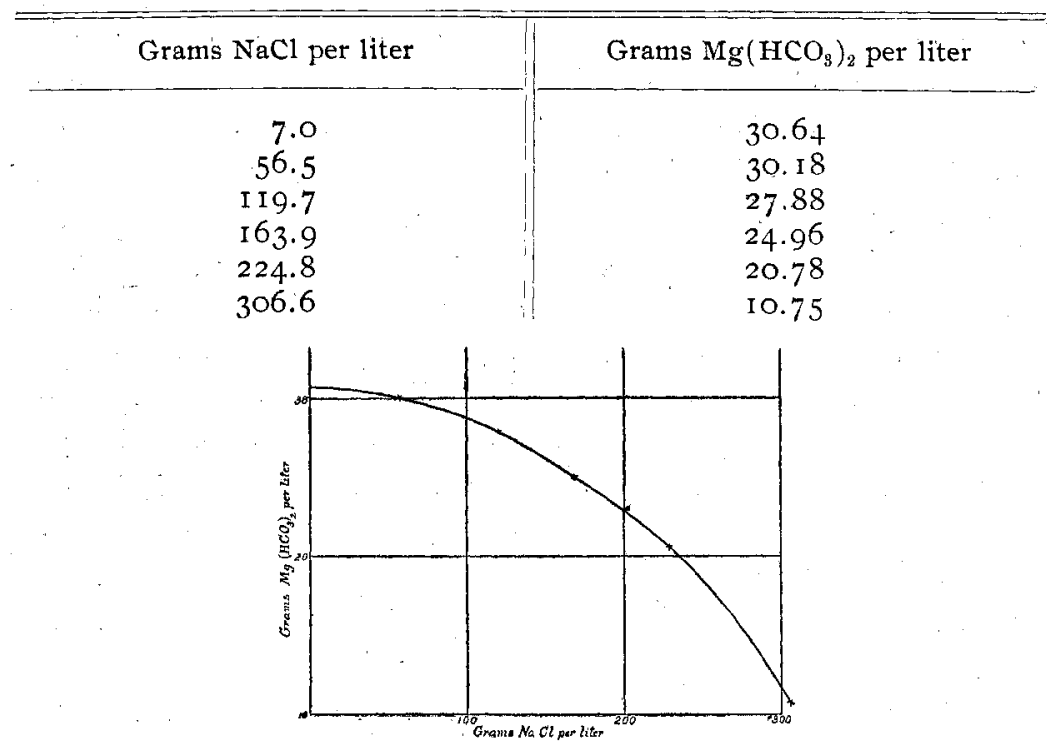

Fig. 2

The first experiment made upon a series of solutions prepared and saturated with carbon dioxide as described abovegave results which, when plotted on cross-section paper, yielded a very smooth curve throughout its whole length. From this curve it appears that the solubility of magnesium bicarbonate is greatest in pure water, being about 3.06 grams $\mathrm{Mg}\left(\mathrm{HCO}_{3}\right)_{2}$ per roo cc, and decreases gradually as the concentration of sodium chloride 
increases, to about one-third the above amount in a nearly saturated solution of sodium chloride. When this experiment was subsequently repeated, however, under as nearly similar conditions as possible, the curve obtained was somewhat irregular and, in addition, lay for most of its length below the one plotted for the results obtained from the analysis made upon the first series of solutions. The solubility of magnesium bicarbonate in pure water, as determined the second time, was only about 2.0 grams per Ioo cc, instead of 3.0 grams as found above. In the second experiment, although the course of the curve was more or less irregular, it descended, as had the first, as the concentration of the sodium chloride ascended. The solubility, as found for the nearly saturated sodium chloride solution, was very nearly the same in the two instances. It was not deemed worth while to record the results obtained with the second series of solutions which undoubtedly did not represent final equilibria conditions. They are cited to illustrate the difficulties to be expected when working with magnesium carbonate, and the ten. dency toward what are probably "false equilibria" when the substance is dissolved in solutions of more soluble salts.

It will be further observed that, assuming this to be the case of the solubility of magnesium bicarbonate, $\left[\mathrm{Mg}\left(\mathrm{HCO}_{3}\right)_{2}\right]$, and sodium chloride, $(\mathrm{NaCl})$, it is one where there is a decreasing solubility of the one salt with the increasing concentration of the other, although no common ion is yielded by the dissociation of the two solutes. No reasonable explanation of this discrepancy with the indications of the hypothesis of electrolytic dissociation suggests itself, and it is probable that this case may be regarded as a real exception to the hypothesis.

One more experiment with solutions of magnesium carbonate and a soluble salt in contact with an atmosphere of carbon dioxide will be cited. In this case the soluble salt used was sodium sulphate instead of the chloride. The saturation with carbon dioxide was accomplished exactly as has been noted for the two experiments already described. The carbon dioxide was introduced into the solutions at room temperature, and the 
temperature of the shaking apparatus kept the same at each period of shaking until the last, when the temperature was raised to $37.5^{\circ}$ and the bottles revolved for forty hours at this temperature. It was noted that as each bottle was unstoppered the difference in the ease with which each of the stoppers could be withdrawn indicated a different gas pressure inside each bottle. Another and more striking evidence of the gas pressure existing in each bottle was found in the fact that, on removing the stoppers, bubbles of gas could be seen ascending from the solid magnesium carbonate in the bottom of each bottle, and in most cases it was evolved at such a rate that the solid material itself was dispersed throughout the liquid. This increased gas pressure resulted, no doubt, from the fact that each solution had been. saturated with carbon dioxide at a temperature of about $20^{\circ} \mathrm{C}$, and afterwards subjected for a long time to a temperature of $37.5^{\circ}$, whereupon a varying amount of carbon dioxide was liberated from each solution and created a slightly different gas pressure in each bottle. The results of the titrations of these solutions with standard half-normal acid solutions, using methyl orange as indicator, showed that the amount of magnesium bicarbonate dissolved in Ioo cc of pure water, and in each of the sodium sulphate solutions was very nearly the same in all. The variations being from $\mathrm{I} .463$ grams in the pure water to I.9I6 grams, being the highest amount and found in a solution of a concentration of about I 2 percent sodium sulphate, the amount of the bicarbonate then decreasing very gradually to about $\mathrm{I} .6 \mathrm{I} 2$ grams in a saturated solution of sodium sulphate.

\section{In Equilibrium with an Atmosphere Free from Carbon Dioxide}

In Solutions of Sodium Chloride. - A series of solutions of sodium chloride was prepared, and solid magnesium carbonate added in about the proportion of 2 grams of solid to each roo cc of solution. The solutions were all brought to vigorous boiling, transferred to bottles, which were then closed with rubber stoppers, and allowed to cool. It was thought wiser to momentarily remove the stoppers, from time to time, during the cooling in order to equalize the pressures within the bottles, and possibly traces 
of carbon dioxide may have thus found entrance and been absorbed by the solutions. On cooling, the solutions were vigorously agitated for about 3 days at a temperature of $23^{\circ} \mathrm{C}$, allowed to stand until the major part of the suspended solid material had subsided and quickly filtered. Aliquot portions of the solution were then weighed and analyzed by the methods indicated above. It was assumed that the magnesium went into solution in the form of the carbonate alone, and that the resultant solution would therefore contain only normal carbonates and no bicarbonates. Titrations with a standard acid, using phenolphthaleine and methyl orange respectively as indicators, showed this assumption to be not quite true and that small amounts of bicarbonates probably existed in all the solutions, but in amounts so small as to be negligible. Repeated experiments showed that vigorous boiling of the solution containing suspended solid was necessary to eliminate the excess of carbon dioxide and decompose the last traces of hydrogen carbonate. The results obtained are given in the following table and represented graphically in the accompanying chart.

Solubility of Magnesium Carbonate in Aqueous Solutions of Sodium Chloride

\begin{tabular}{|c|c|c|c|c|}
\hline $\begin{array}{l}\text { Weight of liter } \\
\text { of solution }\end{array}$ & $\begin{array}{c}\text { Grams } \mathrm{NaCl} \\
\text { per liter }\end{array}$ & $\underset{\text { per liter }}{\operatorname{Grams}} \mathrm{MgCO}_{3}$ & $\begin{array}{c}\text { Reacting } \\
\text { weights. } \\
\mathrm{NaCl} \text { perliter }\end{array}$ & $\begin{array}{c}\text { Reacting } \\
\text { weights. } \\
\mathrm{MgCO}_{3} \text { per } \\
\text { liter }\end{array}$ \\
\hline 996.92 & 0.0 & 0.176 & 0.000 & 0.00210 \\
\hline 1016.82 & 28.0 & 0.418 & 0.482 & 0.00500 \\
\hline 1041.09 & 59.5 & 0.527 & I.025 & 0.00630 \\
\hline 1070.50 & 106.3 & 0.585 & 1.831 & 0.00699 \\
\hline 1094.53 & 147.4 & 0.544 & 2.539 & 0.00650 \\
\hline I 142.48 & $23 \mathrm{III}$ & 0.460 & $3.98 \mathrm{I}$ & 0.00550 \\
\hline I I 70.14 & 272.9 & 0.393 & $4.7 \mathrm{OI}$ & 0.00470 \\
\hline I I 99.28 & $33 \mathrm{I} .4$ & 0.293 & $5.7 \circ 9$ & $0.0035^{\circ}$ \\
\hline
\end{tabular}

It will be observed that with increasing concentration of sodium chloride up to about a I 2 percent solution, there is an increase in the solubility of magnesium carbonate, but as the concentration of sodium chloride further increases there is a gradual diminution of the solubility of the magnesium carbonate, yield- 
ing a solubility curve with a maximum point, being, in this respect, analogous to the curve representing the solubility of calcium carbonate in solutions of sodium chloride.

In Solutions of Sodium Sulphate. - A series of solutions of sodium sulphate was prepared, magnesium carbonate added, and then treated exactly as the sodium chloride series just described, except that instead of chlorine determinations, the sulphates present in the various solutions were estimated as barium sulphate precipitated from appropriate portions of the solutions. After having satisfactorily determined the solubility curve at $23^{\circ} \mathrm{C}$, another series of solutions was prepared, brought to equilibrium at $35.5^{\circ} \mathrm{C}$ and analyzed. The results brought out the unlooked-for fact that the solubility of magnesium carbonate in solutions of sodium sulphate is decreased by increasing the temperature, and that the solubility curve at $35.5^{\circ}$ is lower at every point than the one corresponding to $23^{\circ} \mathrm{C}$. The curves are similar in general respects to that representing the solubility of calcium carbonate in solutions of sodium sulphate. The results obtained are tabulated below and are graphically represented in Figure 3 .

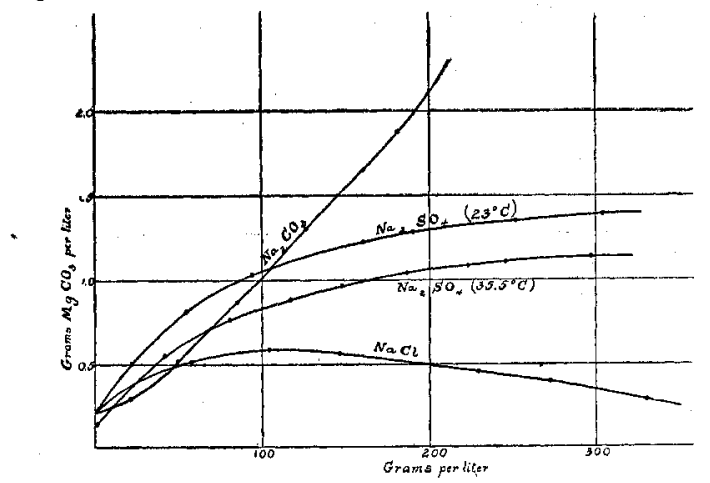

Fig. 3 .

In Solutions of Sodium Carbonate. - A series of solutions was prepared by dissolving anhydrous normal sodium carbonate in water which had been previously boiled to expel dissolved carbon dioxide, magnesium carbonate added as in the series above described. The solutions were not boiled subsequent to 
Solubility of Magnesium Carbonate in Aqueous Solutions of Sodium Sulphate

At $24^{\circ} \mathrm{C}$.

\begin{tabular}{|c|c|c|c|c|}
\hline $\begin{array}{l}\text { Weight of liter } \\
\text { of solution }\end{array}$ & $\begin{array}{c}\text { Grams } \mathrm{Na}_{2} \mathrm{SO}_{4} \\
\text { per liter }\end{array}$ & ${ }_{4}^{4}$ prams $\mathrm{MgCO}_{3}$ & $\begin{array}{l}\text { Reacting } \\
\text { weights. } \\
\mathrm{Na}_{2} \mathrm{SO}_{4} \text { per } \\
\text { liter }\end{array}$ & $\begin{array}{c}\text { Reacting } \\
\text { weights. } \\
\mathrm{MgCO}_{3} \text { per } \\
\text { liter }\end{array}$ \\
\hline 997.52 & 0.00 & 0.216 & 0.000 & $0.0025^{8}$ \\
\hline 1021.24 & 25.12 & $0.5^{86}$ & o. I 78 & 0.00700 \\
\hline 1047.60 & 54.76 & 0.828 & 0.388 & 0.00990 \\
\hline 1080.95 & 95.68 & 1.020 & 0.678 & 0.01219 \\
\hline I I 33.85 & 160.80 & I. 230 & I. I 40 & 0.01470 \\
\hline I I 57.34 & 191.90 & 1. 280 & I. 360 & 0.01530 \\
\hline I 206.03 & 254.60 & I. $33^{8}$ & 1.804 & 0.01600 \\
\hline I $223.9 \mathrm{I}$ & 278.50 & I. $33^{8}$ & 1.973 & 0.01600 \\
\hline I 241.99 & 305.10 & I. 388 & 2.162 & 0.01660 \\
\hline \multicolumn{5}{|c|}{ At $35.5^{\circ} \mathrm{C}$. } \\
\hline 995.15 & $0.3^{2}$ & $0.13 I$ & - & 0.00156 \\
\hline $\mathrm{IO}_{32.89}$ & 41.84 & 0.577 & 0.296 & 0.00689 \\
\hline 1067.23 & 81.84 & 0.753 & 0.579 & 0.00900 \\
\hline I094.77 & II $6.5^{6}$ & 0.904 & 0.826 & 0.01080 \\
\hline I I $20.3^{8}$ & I 48.56 & 0.962 & 1.052 & 0.01149 \\
\hline I I $5 \mathrm{I} .7 \mathrm{O}$ & 186.70 & I. .047 & 1.323 & $0.0125 I$ \\
\hline I I 79.82 & 224.00 & 1.088 & I. 587 & 0.01300 \\
\hline I 196.32 & 247.20 & I. 100 & $1.75 \mathrm{I}$ & 0.01314 \\
\hline 1236.52 & 299.20 & I. I 30 & 2.120 & 0.01350 \\
\hline
\end{tabular}

the addition of the magnesium carbonate, but were at once tightly stoppered in appropriate bottles and shaken vigorously and continuously for 3 days. After coming to equilibrium, they were anlalyzed, the magnesium being precipitated as the double ammonium phosphate in the presence of a large excess of ammonia and ammonium chloride, and the amount of carbonates being determined by titrating with a standard solution of hydrochloric acid, using methyl orange as indicator. From these data the total amounts per $100 \mathrm{cc}$ of solution of sodium and magnesium carbonates present were computed and compared with actual determinations made by evaporating roo $\mathrm{cc}$ portions of the solutions to dryness in weighed platinum dishes, heating cautiously below dull redness to expel water of crystallization, 
but not combined carbon dioxide, and weighing the residues. The figures obtained in this comparison follow:

\begin{tabular}{c|c}
\hline \hline Found & Computed \\
\hline 0.0520 & - \\
2.36 & 2.34 \\
5.11 & 5.13 \\
8.66 & 8.73 \\
12.74 & 12.86 \\
16.05 & 16.24 \\
18.42 & 18.39 \\
21.62 & 21.55
\end{tabular}

From the analysis as above described the results presented in the accompanying table were obtained, and from them the curves given in the diagram (Fig. 3) were plotted.

Solubility of Magnesium Carbonate in Aqueous Solutions of Sodium Carbonate at $25^{\circ} \mathrm{C}$.

\begin{tabular}{|c|c|c|c|c|}
\hline $\begin{array}{l}\text { Weight of liter } \\
\text { of solution }\end{array}$ & $\underset{\text { per liter }}{\text { Grams } \mathrm{Na}_{2} \mathrm{CO}_{3}}$ & $\underset{\text { per liter }}{\mathrm{Grams}} \mathrm{MgCO}_{3}$ & $\begin{array}{l}\text { Reacting } \\
\text { weights. } \\
\mathrm{Na}_{2} \mathrm{CO}_{3} \text { per } \\
\text { liter }\end{array}$ & $\begin{array}{l}\text { Reacting } \\
\text { weights. } \\
\mathrm{MgCO}_{\mathrm{g}} \text { per } \\
\text { liter }\end{array}$ \\
\hline 996.84 & 0.00 & 0.223 & 0.000 & 0.00266 \\
\hline 1019.89 & 23.12 & 0.288 & 0.220 & 0.00344 \\
\hline 1047.72 & 50.75 & 0.510 & 0482 & 0.00620 \\
\hline 1082.47 & 86.42 & 0.879 & 0.820 & 0.01027 \\
\hline I I I 8.9 I & I $27.3^{\circ}$ & 1.314 & 1.209 & 0.01570 \\
\hline I I 47.66 & 160.80 & I. 636 & 1.526 & 0.01955 \\
\hline I I 66.05 & 181.90 & 1.972 & 1.727 & 0.02357 \\
\hline I 189.38 & 213.20 & 2.317 & 2.024 & 0.02770 \\
\hline
\end{tabular}

It will be observed that, except for the lower concentrations, the increase in solubility of the magnesium carbonate with increase in the amount of sodium carbonate is represented by an approximately straight line.

It appears striking that the solubility of magnesium carbonate should increase so rapidly with the increase in the concentration of the sodium carbonate, since we are dealing with a pair of electrolytes supposedly having a common ion. Such cases as this have been found, however, in the previous work 
which has been done in this laboratory and elsewhere, and in former instances an explanation based upon the formation of double salts has been the one usually offered. An unsatisfactory feature of most of these cases, as with the present one, is that an inspection of the residue as solid phase in contact with the solution does not give any evidence of the formation of a new component, nor is there any sudden change in the direction of the solubility curve, indicating the formation of a new component at any particular concentration. Such component, though formed, would not necessarily separate, however, should it possess a relatively high solubility. At present there does not appear any satisfactory method of testing this or any other explanation of the phenomena which has been suggested. It seems wisest, therefore, to refrain from speculation until suffcient data of this kind have been accumulated to furnish possibly a clearer insight of the phenomena.

\section{Conclusions}

In this paper it has been shown:

I. That when appreciable quantities of carbon dioxide are present in the vapor phase in contact with solid magnesium carbonate and solutions of other salts, there is a marked tendency toward conditions of false equilibria. The usual explanation advanced to account for these observations, that double carbonates are formed, is unsatisfactory.

2. The solubility of magnesium carbonate in solutions of sodium chloride when in contact with ordinary air, increases with increasing concentration of sodium chloride up to a maximum and then decreases.

3. The solubility of magnesium carbonate, as the bicarbonate, in solutions of sodium chloride when in contact with an atomsphere containing only carbon dioxide and water vapor at atmospheric pressure, decreases regularly with increasing concentration with respect to sodium chloride. This appears to be a real exception to the hypothesis of electrolytic dissociation for which no explanation based upon that hypothesis can be offered.

4. The solubility of magnesium carbonate in solutions of 
sodium sulphate, in contact with an atmosphere containing only carbon dioxide and water, increases slightly and then decreases with increasing concentrations of sodium sulphate.

5. In contact with an atmosphere free from carbon dioxide, the solubility of magnesium carbonate increases to a maximum and then decreases, with increasing concentration of sodium chloride; it increases regularly with increasing concentration with respect to either sodium sulphate or sodium carbonate.

6. The solubility of magnesium carbonate in solutions of sodium sulphate, in contact with an atmosphere free from carbon dioxide, appears to decrease with increasing temperature.

7. The solubility curve for magnesium carbonate in solutions of sodium carbonate is not in apparent accord with the theory of electrolytic dissociation.

Bureau of Soils,

U.S. Department of Agriculture, Washington, D. C. 